\title{
Faringotonsilite estreptocócica: necessidade do uso de testes microbiológicos para diagnóstico preciso
}

\author{
Streptococcal pharyngotonsillitis: need of microbiological tests in order to have a precise diagnosis
}

Maria Isabel de Moraes-Pinto

Faringotonsilite aguda é uma infecção comum na faixa etária pediátrica, facilmente reconhecida por meio da anamnese e exame físico. É de etiologia viral, na maioria dos casos, sendo causada pelo estreptococo beta-hemolítico do grupo A (EBHA) somente em 20 a $30 \%$ dos quadros que ocorrem em crianças ${ }^{(1,2)}$.

Devido à baixa sensibilidade e especificidade da avaliação clínica no diagnóstico etiológico de infecção pelo EBHA, diversas entidades médicas, tais como a Sociedade Brasileira de Pediatria e a Academia Americana de Pediatria, recomendam atualmente que o diagnóstico de faringotonsilite em pacientes com suspeita clínico-epidemiológica de infecção pelo EBHA seja confirmado por meio do uso de técnicas microbiológicas ${ }^{(3,4)}$.

Esta necessidade é claramente demonstrada em estudo prospectivo publicado neste número da Revista Paulista de Pediatria, por Cardoso et al( ${ }^{(5)}$. Avaliando 650 crianças e adolescentes, os autores mostram que o diagnóstico etiológico de faringotonsilite causada pelo EBHA, se baseado unicamente em dados clínicos, tem baixa sensibilidade e especificidade, diferentemente do que acontece com o diagnóstico realizado por meio da prova rápida para pesquisa de EBHA em secreção de orofaringe $\mathrm{e}^{(5)}$.

Cardoso et al (2012) demonstram que, também em nosso meio, e à semelhança de outro trabalho realizado no Brasil ${ }^{(6)}$, as técnicas microbiológicas têm utilidade para determinar a conduta frente a um caso de faringotonsilite aguda ${ }^{(5)}$. Como se sabe, o tratamento com antibióticos visa à prevenção da febre reumática aguda, de complicações supurativas, como abscesso peritonsilar e linfadenite cervical, além de diminuir o tempo de doença e o período de transmissão para os contatos próximos ${ }^{(4)}$. Por outro lado, o tratamento inapropriado da faringotonsilite aguda com antibióticos é um dos fatores que contribuem para o aumento da incidência de resistência antimicrobiana ${ }^{(7,8)}$.

O estudo de Cardoso et al ${ }^{(5)}$ está sendo publicado no momento em que a Sociedade Americana de Doenças Infecciosas acaba de lançar uma atualização da sua orientação de conduta para o diagnóstico e tratamento de faringite estreptocócica do grupo A, em que se reforça o uso do teste rápido e/ou da cultura de secreção de orofaringe para o correto diagnóstico etiológico da faringotonsilite estreptocócica ${ }^{(9)}$.

Ao comentarem o uso indiscriminado de antibióticos em nossos dias, Gonzáles et al ${ }^{(10)}$ sugerem que isto seja o resultado da falha em colocar uma evidência em prática. No caso da faringotonsilite estreptocócica, as evidências tanto fora do Brasil quanto em nosso meio ${ }^{(5,6)}$ parecem apontar para a necessidade do uso de testes microbiológicos para a realização de um diagnóstico mais preciso.
Professora Livre Docente do Departamento de Pediatria; Chefe do Laboratório de Pesquisas da Disciplina de Infectologia Pediátrica da Escola Paulista de Medicina da Universidade Federal de São Paulo (UNIFESP), São Paulo, SP, Brasil

\author{
Endereço para correspondência: \\ Maria Isabel de M. Pinto \\ Laboratório de Pesquisas, Disciplina de Infectologia Pediátrica \\ Rua Pedro de Toledo, 781, $9^{\circ}$ andar \\ CEP 04039-032 - São Paulo/SP \\ E-mail: m.isabelmp@uol.com.br \\ Conflito de interesse: nada a declarar
}

Recebido em: 19/11/2012 


\section{Referências bibliográficas}

1. Bisno AL. Acute pharyngitis: etiology and diagnosis. Pediatrics 1996;97:949-54.

2. Ebell MH, Smith MA, Barry HC, Ives $\mathrm{K}$, Carey M. The rational clinical examination. Does this patient have strep throat? JAMA 2000;284:2912-8.

3. Nascimento-Carvalho CM, Marques HH. Recomendação do departamento de Infectologia da Sociedade Brasileira de Pediatria para conduta de crianças e adolescentes com faringoamigdalites agudas. J Pediatr (Rio J) 2006;82:79-80.

4. American Academy of Pediatrics. In: Pickering LK, Baker CJ, Kimberlin DW, Long SS, editors. Group A streptococcal infections. Red Book: 2012. Report of the Committee on Infectious Diseases. $29^{\text {th }}$ ed. Elk Groove Village: American Academy of Pediatrics; 2012. p. 668-80.

5. Cardoso DM, Gilio AE, Hsin SH, Machado BM, De Paulis M, Lotufo JP et al. Impacto do uso da prova rápida para estreptococo beta hemolítico do grupo A no diagnóstico e tratamento da faringotonsilite aguda em Pronto Socorro de Pediatria. Rev Paul Pediatr 2013;31:4-9.
6. dos Santos AG, Berezin EN. Comparative analysis of clinical and laboratory methods for diagnosing streptococcal sore throat. J Pediatr (Rio J) 2005;81:23-8.

7. Grijalva CG, Nuorti JP, Griffin MR. Antibiotic prescription rates for acute respiratory tract infections in US ambulatory settings. JAMA 2009;302:758-66.

8. Butler CC, Simpson SA, Dunstan F, Rollnick S, Cohen D, Gillespie D et al Effectiveness of multifaceted educational programme to reduce antibiotic dispensing in primary care: practice based randomized controlled trial. BMJ 2012; 344:d8173.

9. Shulman ST, Bisno AL, Clegg HW, Gerber MA, Kaplan EL, Lee G et al. Clinical practice guideline for the diagnosis and management of group a streptococcal pharyngitis: 2012 update by the infectious diseases society of america. Clin Infect Dis 2012;55:e86-e102.

10. Gonzales R, Ackerman S, Handley M. Can Implementation Science help to overcome challenges in translating judicious antibiotic use into practice? Arch Intern Med 2012;172:1471-3. 